\title{
FINITE ELEMENT ANALYSIS OF CONTRIBUTING FACTORS TO THE HORIZONTAL SPLITTING CRACKS IN CONCRETE CROSSTIES PRETENSIONED WITH SEVEN-WIRE STRANDS
}

\author{
Hailing Yu \\ Structures and Dynamics Division \\ John A. Volpe National Transportation Systems Center \\ U.S. Department of Transportation \\ Cambridge, MA 02142, U.S.A.
}

\section{ABSTRACT}

This paper employs the finite element (FE) modeling method to investigate the contributing factors to the "horizontal" splitting cracks observed in the upper strand plane in some concrete crossties made with seven-wire strands. The concrete tie is modeled as a concrete matrix embedded with prestressing steel strands. A damaged plasticity model that can predict the onset and propagation of tensile degradation is applied to the concrete material. An elasto-plastic bond model developed inhouse is applied to the steel-concrete interface to account for the interface bond-slip mechanisms and particularly the dilatational effects that can produce the splitting forces. The pretension release process is simulated statically, followed by the dynamic simulations of cyclic rail seat loading. The concrete compressive strength at which the pretension in the strands is released, or release strength, affects both the concrete behavior and the bond characteristics. Three concrete release strengths, 3500, 4500 and $6000 \mathrm{psi}$, are considered in the simulations. Concrete tie models without and with a fastening system are developed and simulated to examine the effect of embedded fastener shoulders and fastener installation. The fastener shoulders are seated relatively deeply reaching between the two rows of strands.

There is instant concrete material degradation adjacent to the strand interfaces near the tie ends upon pretension release. Without the fastening system in the model, the 3500 psi release strength leads to a high degree of degradation that is coalesced and continuous in the upper and lower strand planes, respectively. The damage profiles with the higher release strengths are more discrete and disconnected. Dynamic loading appears to increase the degree of degradation over time. In all cases, the upper strand plane is not dominant in the degree or the extent of material degradation, in contrast to the field observations that the horizontal splitting occurred in the upper strand plane only.

Further simulations with the fastener model at $3500 \mathrm{psi}$ concrete release strength indicate that the fastener installation process does not worsen the damage profile. However, the presence of fastener shoulders in the concrete matrix changes the stress distribution and redirects more concrete damages to the upper strand plane, while leaving disconnected damages in the lower strand plane. Under repeated dynamic rail loading, this potentially reproduces the exact upper strand plane, horizontal cracking pattern observed in the field. Subjected to further experimental verification, the FE analyses identify three contributing factors to the horizontal macro-cracks occurring at the specific upper strand level: (1) relatively low concrete release strength during production, (2) embedded fastener shoulders that redistribute concrete damages to the upper strand plane, and (3) a sufficiently large number of dynamic rail loading cycles for the microscopic damages to develop into macro-cracks. The number of dynamic loading cycles needed to produce macro-cracks should increase with the increased concrete release strength.

\section{INTRODUCTION}

Concrete ties are a promising alternative to traditional timber ties with their many perceived advantages. They can be engineered to meet specific service requirements and add overall stability and performance to a track. They are estimated to last twice as long as timber ties and therefore result in lowered life cycle costs despite a higher initial cost. However, since their first major installation in North America in 1966 [1], prestressed concrete ties have displayed several failure modes in the field 
that have led to premature replacement of track components and sometimes derailment accidents [2]. These failures have prevented more widespread use of the concrete ties.

A class of concrete crossties made with eight prestressing strands arranged in two rows have shown a type of "horizontal" splitting cracks in track. These cracks appear to initiate near the end of a concrete tie and propagate toward the rail seat in a plane across the top row strands, thus giving the "horizontal" appearance. It is well-known that wide spread horizontal cracks led to large scale replacement of the pre-2003 concrete ties on the Amtrak's Northeast Corridor [3]. Figure 1 shows two typical examples of such cracks. It is generally believed that these cracks were caused by the splitting forces transmitted from the prestressing strands to the surrounding concrete, but the exact factors and conditions contributing to the distinct features of the "horizontal" cracks remain poorly understood. This has impeded informed development of concrete tie performance standards that can fully address such failures.

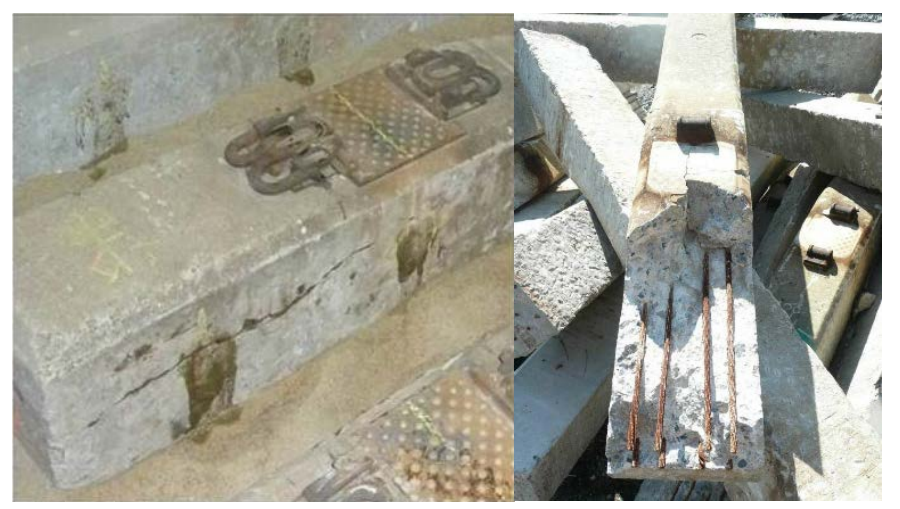

Figure 1: Horizontal splitting cracks in concrete crossties on Amtrak's Northeast Corridor [3].

Concrete crossties are made by embedding prestressing steel reinforcements in concrete and releasing the pretension in the reinforcements once desired concrete strength is achieved. Releasing the pretension leads to enlarged diameters of the steel reinforcements and hence dilated steel-concrete interfaces owing to the Hoyer effect. Further, natural or manufactured surface indentations on steel reinforcements can produce additional interface dilatations, which can transmit splitting forces and lead to splitting cracks in concrete. The natural spiral surfaces of steel strands introduce sufficient interface dilatational effects that can strengthen the steel-concrete bond but also increase the risk of concrete bursting/splitting failure.

This paper applies the finite element analysis (FEA) method to study the probable contributing factors to the horizontal cracks observed on the Northeast Corridor's concrete crossties, which were pretensioned with two rows of seven-wire strands. The Volpe Center has developed an FEA framework, including damaged plasticity modeling of concrete, interface bond model development for the steel reinforcement-concrete interface and modeling of the ballast and subgrade support, to predict and evaluate concrete crosstie performance. Earlier work treated the interface as a linear elastic material [4-5]. To reproduce the interface bond-slip and dilatational mechanisms more accurately, elastoplastic FE bond models were developed for various reinforcement interfaces, including those of a smooth wire, a seven-wire strand and three indented wires [6-8]. Most recently, unified elastoplastic formulations were developed and implemented to characterize the bond behavior of the diversity of reinforcements described above using one bond model [9]. The FEA framework updated with these elastoplastic bond models has been applied to evaluate the center negative flexural performance [10-11] and predict the surface deflection profiles of concrete ties [12]. This paper further illustrates that this more sophisticated bond modeling approach can help to improve the understanding of concrete splitting failures by accounting for the various degrees of bond and dilatational effects in the interface.

\section{FINITE ELEMENT ANALYSIS FRAMEWORK}

The commercial FEA software Abaqus was employed [13]. In this section, the geometric and reinforcement configurations of the concrete crosstie under consideration was first described. Then the respective FE modeling of the concrete material, bond, and the ballast and subgrade support was discussed. The fastener presence and its potential effect on the concrete cracking behavior were also considered. Finally, the static and dynamic FEA approaches and their limitations were discussed.

\section{Concrete tie description}

Figure 2 shows the geometric dimensions of a typical concrete crosstie. The geometric parameters of the concrete tie studied in this paper are shown in Table 1. There were eight seven-wire strands arranged in two rows in the tie, and they were initially pretensioned to 17.21 kips $(76,554 \mathrm{~N})$ per strand, equivalent to a nominal initial tensile stress of $156 \mathrm{ksi}(1,075.6$ $\mathrm{MPa}$ ). The steel strands had a yield strength of $270,600 \mathrm{psi}$ $(1,865.7 \mathrm{MPa})$.

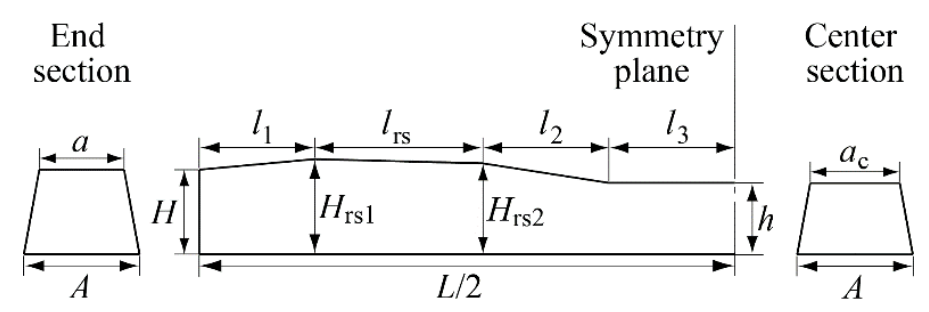

Figure 2: Geometric dimensions of a typical concrete crosstie.

Table 1. Geometric parameters of the concrete tie under consideration.

\begin{tabular}{lll}
\hline \multirow{2}{*}{$a, a_{\mathrm{c}}, A$} & (in.) & $8.980,9.375,10.375$ \\
\cline { 2 - 3 } & (mm) & $228.1,238.1,263.5$ \\
\hline \multirow{2}{*}{$H, H_{\mathrm{rs} 1}, H_{\mathrm{rs} 2}, h$} & (in.) & $9.938,9.825,9.425,7.125$ \\
\cline { 2 - 3 } & (mm) & $252.4,249.6,239.4,181.0$ \\
\hline \multirow{2}{*}{$l_{1}, l_{\mathrm{r} s}, l_{2}, l_{3}, L / 2$} & (in.) & $13.125,16,9,12.875,51$ \\
\cline { 2 - 3 } & (mm) & $333.4,406.4,228.6,327.0,1295.4$ \\
\hline Rail seat cant & \multicolumn{1}{c}{$1: 40$} \\
\hline
\end{tabular}




\section{Concrete material modeling}

A damaged plasticity model was applied in the material modeling of the concrete. The model uses isotropic damaged elasticity in combination with isotropic tensile and compressive plasticity to represent the inelastic behavior of concrete [13]. Tensile and compressive damages in concrete are characterized as strength degradations and represented by tensile and compressive damage variables, respectively. As indicated by the tensile stress-strain curve in Figure 3, the tensile damage variable $d_{\mathrm{t}}$ measures the degree of tensile strength degradation in the post peak response, with $d_{\mathrm{t}}=0$ indicating undamaged concrete and $d_{t}=1$ indicating completely degraded tensile strength and formation of macro-cracks.

The constitutive equations and material parameters needed to apply this model were described in previous publications [45]. The engineering specification of the release strength for the concrete tie in this study was around 4,000 psi (27.6 MPa) [3]. In a separate transfer length study conducted on reduced size, pretensioned concrete prisms at Kansas State University (KSU), three nominal release strengths were considered: 3,500, 4,500 and $6,000 \mathrm{psi}(24.1,31.0$ and $41.4 \mathrm{MPa})$ [14]. The basic concrete material properties corresponding to these three release strengths, including elastic modulus, split tensile strength and compressive strength, are summarized in Table 2 and were applied in the FE study in this paper.

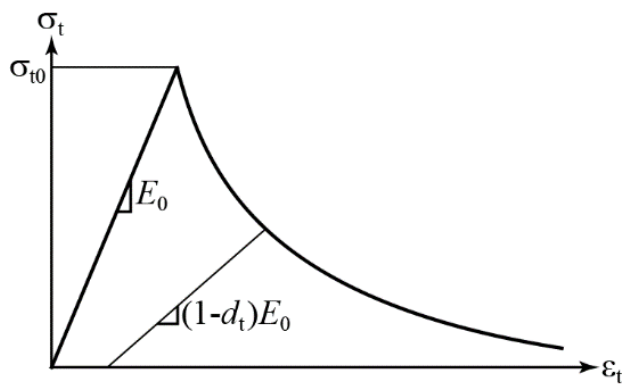

Figure 3: Concrete stress-strain $\left(\sigma_{t}-\varepsilon_{t}\right)$ response to uniaxial tension, and definition of tensile damage variable $d_{t}$.

Table 2. Concrete material properties.

\begin{tabular}{cccc}
\hline $\begin{array}{c}\text { Nominal } \\
\text { release } \\
\text { strength }\end{array}$ & $3500 \mathrm{psi}$ & $4500 \mathrm{psi}$ & $6000 \mathrm{psi}$ \\
\hline $\begin{array}{c}\text { Elastic } \\
\text { modulus } E\end{array}$ & $\begin{array}{c}3,259 \mathrm{ksi} \\
(22.5 \mathrm{GPa})\end{array}$ & $\begin{array}{c}3,655 \mathrm{ksi} \\
(25.2 \mathrm{GPa})\end{array}$ & $\begin{array}{c}4,028 \mathrm{ksi} \\
(27.8 \mathrm{GPa})\end{array}$ \\
\hline Split tensile & $366.0 \mathrm{psi}$ & $439.4 \mathrm{psi}$ & $478.8 \mathrm{psi}$ \\
strength $\sigma_{\mathrm{t} 0}$ & $(2.52 \mathrm{MPa})$ & $(3.03 \mathrm{MPa})$ & $(3.3 \mathrm{MPa})$ \\
\hline Compressive & $3586.0 \mathrm{psi}$ & $4570.2 \mathrm{psi}$ & $5977.8 \mathrm{psi}$ \\
strength $\sigma_{\mathrm{cu}}$ & $(24.7 \mathrm{MPa})$ & $(31.5 \mathrm{MPa})$ & $(41.2 \mathrm{MPa})$ \\
\hline
\end{tabular}

\section{Bond modeling}

The unified elastoplastic bond model [9] was applied in this study to simulate the interface interaction between the sevenwire strand "SA" and concrete. Table 3 shows the complete list of parameters needed to define the bond model. Reference [9] calibrated and validated the bond model parameters based on the untensioned pullout and the pretensioned prism tests conducted under a nominal concrete release strength of 6,000 psi (41.4 $\mathrm{MPa})$ at a concrete tie plant [15]. For concrete release strengths of 3,500 and 4,500 psi $(24.1$ and $31.0 \mathrm{MPa})$, while the pretensioned prism test data were available, the untensioned pullout test data were unavailable because the tests were not conducted; thus additional assumptions were needed to determine the corresponding bond model parameters.

For the two lower concrete release strengths, it was assumed that the bond between the steel strand "SA" and the concrete was not fully developed resulting in lower bond strengths, but the plastic dilatation-to-slip rate was assumed to be the same as a result of similar interface sliding mechanisms. Based on these assumptions, the bond strength related parameters (elastic stiffnesses, coefficient of friction and initial adhesive strength) for the two lower concrete release strengths were simply scaled with those for the $6,000 \mathrm{psi}(41.4 \mathrm{MPa})$ release strength. From calibration with the available pretensioned concrete prism test data [14], the scale factors were determined to be 0.6 and 0.7 , respectively, for the 3,500 and $4,500 \mathrm{psi}(24.1$ and $31.0 \mathrm{MPa})$ release strengths. The remaining parameters were dilatation related and kept the same for all three concrete release strengths. The bond model parameters corresponding to all three concrete release strengths are summarized in Table 4.

Table 3. Bond model parameter nomenclature.

\begin{tabular}{ll}
\hline Parameter & \multicolumn{1}{c}{ Description } \\
\hline$D_{\mathrm{nn}}^{\mathrm{e}}$ & Normal elastic stiffness \\
\hline$D_{\mathrm{ns}}^{\mathrm{e}}\left(D_{\mathrm{nt}}^{\mathrm{e}}\right)$ & Shear elastic stiffness \\
\hline$\mu$ & Coefficient of friction \\
\hline$a_{0}$ & Initial adhesive strength \\
\hline$u_{\mathrm{tc}}^{\mathrm{pl}}$ & $\begin{array}{l}\text { Plastic slip at which adhesive (or cohesive) } \\
\text { state ends }\end{array}$ \\
\hline$\mu_{\mathrm{d}}^{\mathrm{max}}$ & Maximum dilatational coefficient \\
\hline$\mu_{\mathrm{dc}}$ & Dilatational coefficient at $\left|u_{\mathrm{t}}^{\mathrm{pl}}\right|=u_{\mathrm{tc}}^{\mathrm{pl}}$ \\
\hline$u_{\mathrm{td}}^{\mathrm{pl}}$ & $\begin{array}{l}\text { Plastic slip at which dilatational coefficient } \\
\text { reaches zero }\end{array}$ \\
\hline
\end{tabular}

\section{Ballast and subgrade modeling}

The Extended Drucker-Prager plasticity model suitable for simulating granular, frictional materials was applied to the ballast material. The ballast model was assigned homogeneous material properties and no deterioration. A concrete tie was expected to be in a rail seat positive bending mode with such a ballast support condition. The ballast was supported by an elastic subgrade, which was modeled as a sufficiently large rectangular box. The ballast and subgrade were modeled for a width equal to one tie spacing. The tie spacing and the ballast depth were assumed to be $30 \mathrm{in}$. $(762 \mathrm{~mm})$ and 24 in. (609.6 
$\mathrm{mm}$ ), respectively. Table 5 shows the ballast and subgrade material parameters used in modeling. The concrete crosstieballast and ballast-subgrade interactions were modeled using contact definitions with a coefficient of friction of 0.5 . Figure 4 shows the schematic of a quarter symmetric crosstie-ballastsubgrade model.

Table 4. Bond model parameters.

\begin{tabular}{lcccc}
\hline \multicolumn{2}{c}{$\begin{array}{c}\text { Nominal release } \\
\text { strength }\end{array}$} & $3500 \mathrm{psi}$ & $4500 \mathrm{psi}$ & $6000 \mathrm{psi}$ \\
\hline$D_{\mathrm{nn}}^{\mathrm{e}}$ & $\begin{array}{c}\mathrm{lbf} / \mathrm{in}^{3} \\
\left(\mathrm{~N} / \mathrm{mm}^{3}\right)\end{array}$ & $\begin{array}{c}55,578,000 \\
(15,086.5)\end{array}$ & $\begin{array}{c}64,841,000 \\
(17,600.9)\end{array}$ & $\begin{array}{c}92,630,000 \\
(25,144.2)\end{array}$ \\
\hline$D_{\mathrm{ns}}^{\mathrm{e}}\left(D_{\mathrm{nt}}^{\mathrm{e}}\right)$ & $\begin{array}{c}\mathrm{lbf} / \mathrm{in}^{3} \\
\left(\mathrm{~N} / \mathrm{mm}^{3}\right)\end{array}$ & $\begin{array}{c}231,574.8 \\
(62.86)\end{array}$ & $\begin{array}{c}270,170.6 \\
(73.34)\end{array}$ & $\begin{array}{c}385,958 \\
(104.8)\end{array}$ \\
\hline$\mu$ & & 0.18 & 0.21 & 0.3 \\
\hline$a_{0}$ & $\mathrm{psi}$ & 360 & 420 & 600 \\
& $(\mathrm{MPa})$ & $(2.48)$ & $(2.90)$ & $(4.14)$ \\
\hline$u_{\mathrm{tc}}^{\mathrm{pl}}$ & $\mathrm{in.}$ & & 0.08 \\
\hline$\mu_{\mathrm{d}}^{\max }$ & $(\mathrm{mm})$ & $(2.03)$ & \\
\hline$\mu_{\mathrm{dc}}$ & & 0.0036 & \\
\hline$u_{\mathrm{td}}^{\mathrm{pl}}$ & in. & & 0.0036 \\
\hline
\end{tabular}

Table 5. Ballast and subgrade material properties.

\begin{tabular}{cccc}
\hline & $\begin{array}{c}\text { Elastic } \\
\text { modulus }\end{array}$ & $\begin{array}{c}\text { Poisson's } \\
\text { ratio }\end{array}$ & $\begin{array}{c}\text { Yield } \\
\text { strength }\end{array}$ \\
\hline Ballast & $\begin{array}{c}30,168 \mathrm{psi} \\
(208 \mathrm{MPa})\end{array}$ & 0.3 & $\begin{array}{c}58 \mathrm{psi} \\
(0.4 \mathrm{MPa})\end{array}$ \\
\hline Subgrade & $\begin{array}{c}72,519 \mathrm{psi} \\
(500 \mathrm{MPa})\end{array}$ & 0.25 & - \\
\hline
\end{tabular}

\section{Consideration of fastener installation}

Figure 5 shows the schematics of the fastener shoulder, fastener clip and rail assemblies used on the pre-2003 Northeast Corridor concrete ties. The fastener shoulders were deeply embedded inside the concrete. Detailed views of the fastener shoulder design in Figure 6 further shows that there were small protruding parts on the surfaces in contact with the concrete, which were believed to increase the bond of the shoulders with the concrete by design. It was postulated that both the embedment depth and the protruding parts on the shoulder surfaces affect the horizontal cracking behavior of the concrete tie, and therefore they were considered in modeling as well.

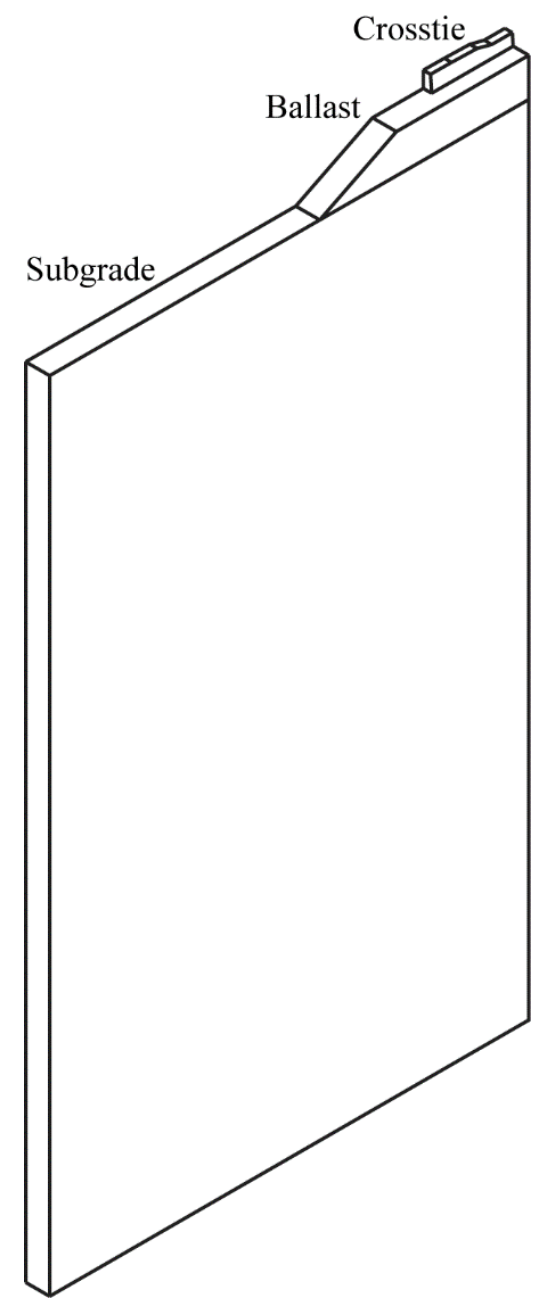

Figure 4: Schematic of a quarter symmetric crosstie-ballastsubgrade model.

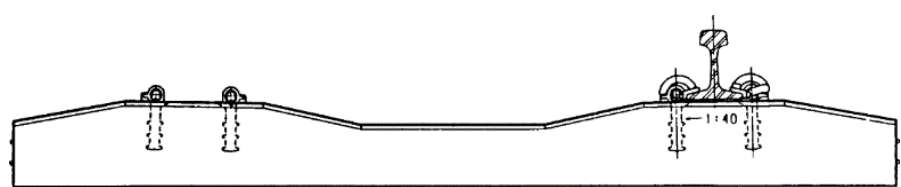

Figure 5: Concrete crosstie with fastener shoulders (left rail seat) and a fastener-rail assembly (right rail seat).

A simplified fastener shoulder model adopted in this study is shown in Figure 6 alongside the actual design. The model kept the depth and important characteristics of the protruding surface parts but avoided reproducing the exact complex geometric features, which can lead to significant computational difficulties. Figure 7 compares the relative position of the fastener shoulder embedment to steel strands in the concrete, by design versus in modeling. Both show that the intrusion of the fastener shoulders goes as deep as between the upper (first) and lower (second) rows of strands. 

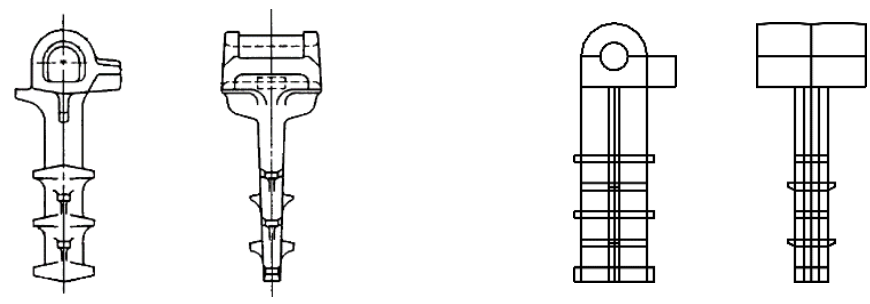

Figure 6: Two views of the fastener shoulder design (left) and the simplified model (right).
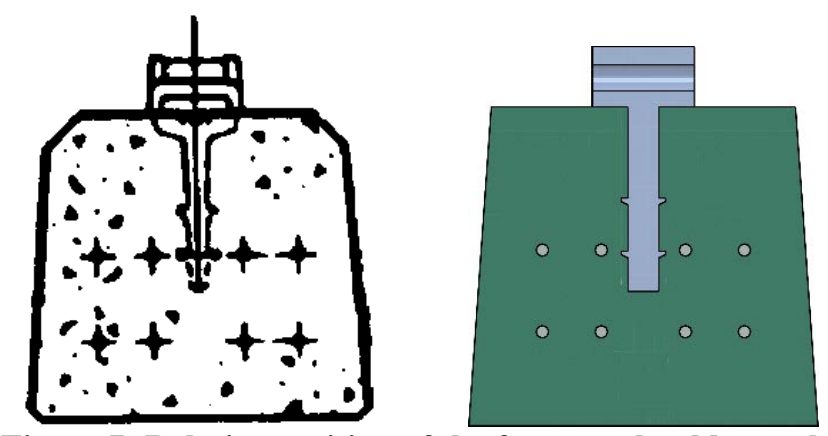

Figure 7: Relative position of the fastener shoulder to the steel strands: actual design (left) versus modeling (right) in a rail seat cross section.

\section{Static versus dynamic analysis}

Concrete crossties are pretensioned concrete members that come with initial stress states as a result of the pretension release or prestress transfer phase during production. The pretension release phase was simulated using the concrete material (Table 2 ) and the bond parameters (Table 4) corresponding to a specific concrete release strength. The initial tension assigned for each strand was $156 \mathrm{ksi}(1,075.6 \mathrm{MPa})$, and it was then released in static analyses resulting in prestress transferred stress states, which in turn were applied as initial conditions in the subsequent dynamic FE analyses.

The dynamic FE analyses simulated the response of the concrete tie with the ballast and subgrade support. The concrete tie was subjected to dynamic rail seat loading either through distributed traction loads over the rail seat area or a point load on the rail when the fastener-rail assembly was included. The resultant rail seat load was set at 62.1 kips $(276.2 \mathrm{kN})$, which was calculated based on an axel load of 82 kips $(364.8 \mathrm{kN})$, a load distribution factor of 0.505 and an impact factor of $200 \%$ [16]. With the assumptions that a railcar passes four tie spacing in the duration of a dynamic load and that each spacing ranges from 20-30 in. (508-762 mm), the dynamic load duration was calculated to vary from $0.075-0.11$ seconds for a railcar traveling at $60 \mathrm{mph}(96.56 \mathrm{~km} / \mathrm{h})$. The dynamic load duration in the simulations was therefore chosen to be 0.1 seconds. Because the dynamic load with this duration did not produce any impact effect in the simulations, the inclusion of the impact factor in calculating the dynamic load appeared to be necessary. This paper has not explored the possibility of achieving the impact effect by varying the duration of the dynamic load.
As shown in Figure 8, in one loading cycle, the rail seat load was increased linearly from 0 to 62.1 kips $(276.2 \mathrm{kN})$ in 0.05 seconds and then deceased linearly to 0 in another 0.05 seconds. Owing to the time consuming nature of the dynamic FEA, simulations of only three repeated load cycles were conducted for each studied scenario.

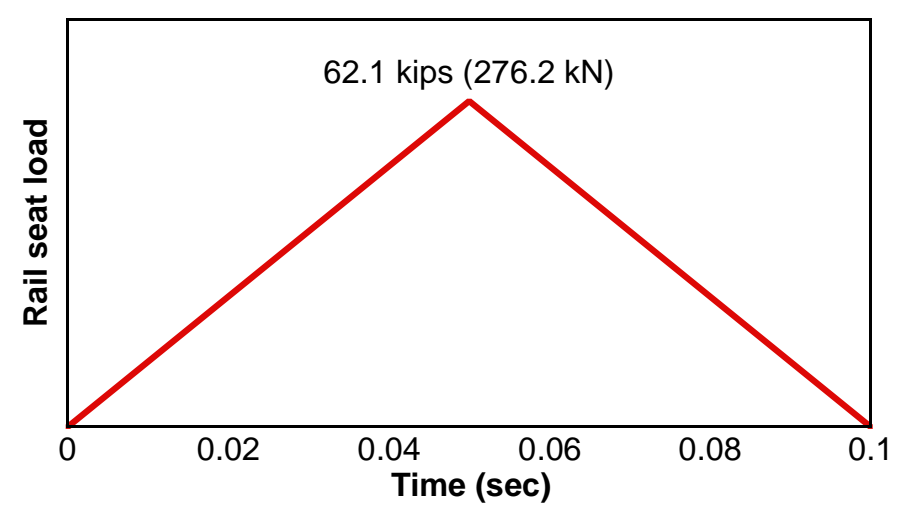

Figure 8: Definition of one dynamic loading cycle.

\section{Limitation}

It is well known that concrete material properties evolve over time. Ideally while the static FEA of the prestress transfer process assumes short term concrete properties (i.e., at release), the dynamic FEA should assume longer term concrete material properties which often feature higher elastic modulus, tensile strength and compressive strength. However, owing to an inflexibility in the FEA program to change material properties between continued analyses, the FEA conducted in this paper assumed the same concrete material properties at release for both short and longer term behaviors. Further, the effects of concrete creep, concrete shrinkage and steel relaxation that can lead to prestress losses were not considered.

\section{RESULTS}

For both the static analyses (of prestress transfer) and the dynamic analyses (of rail seat positive bending), a key outcome examined was the tensile damage profile of concrete indicated by the tensile damage variable $d_{\mathrm{t}}$. Figure 9 shows the $d_{\mathrm{t}}$ contour for elements with $d_{t} \geq 0.05$ after pretension release at the 3,500 psi (24.1 MPa) concrete strength with no presence of fastener shoulders or fastener clips. The maximum $d_{\mathrm{t}}$ was of great interest, because $d_{\mathrm{t}}$ approaching 1 would indicate potential cracking. In addition, the total element volume $\left(V_{\mathrm{dt}}\right)$ and the extent of damage in the length direction $\left(L_{\mathrm{dt}}\right.$, measured from tie end as shown in Figure 9) for the concrete elements with $d_{t}$ exceeding a certain threshold (e.g., $d_{\mathrm{t}} \geq d_{\mathrm{t}, \mathrm{min}}$ ) can be calculated to assess the spatial extent of the concrete damage. The evolution of the tensile damage profile after experiencing cyclic dynamic loading was further evaluated for their potential to develop into macro-cracks. 


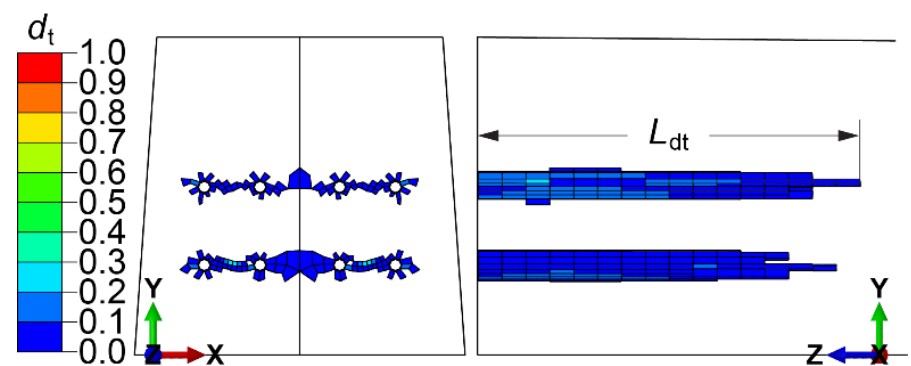

Figure 9: Tensile damage profile $\left(d_{t} \geq 0.05\right)$ after pretension release at 3,500 psi (24.1 $\mathrm{MPa})$ release strength without fastener installation.

\section{Without fastener installation}

Simulations were first conduced for a concrete tie model without the presence of fastener shoulders or clips. A quarter of the actual tie was modeled due to symmetries about the center cross sectional and longitudinal planes. The static simulations were conducted under three concrete release strengths: 3,500, 4,500 and 6,000 psi (24.1, 31.0 and 41.4 MPa). Each static simulation was then continued for three cycles of dynamic FEA under the loading depicted in Figure 8. In addition to the $d_{\mathrm{t}}$ contour shown in Figure 9 for the 3,500 psi $(24.1 \mathrm{MPa})$ release strength, Figure 10 shows those for the 4,500 and 6,000 psi (31.0 and $41.4 \mathrm{MPa}$ ) release strengths, respectively, after pretension release. The symmetric cross-sectional contours were mirrored to show full cross-sectional views in these figures. Figure 11 shows the evolution of the maximum $d_{\mathrm{t}}$ and the damage length $L_{\mathrm{dt}}$ from the pretension release and dynamic loading phases. Dynamic loading (in particular at lower release strengths and after the first dynamic cycle) appeared to increase both the maximum $d_{\mathrm{t}}$ and the extent of damage. Although the extent of damage might have been overestimated because of the continued use of concrete release properties as opposed to longer term properties during the dynamic loading phase, the prediction of the increased potential to crack (maximum $d_{t}$ ) was more reasonable because the initial damages presented irreversibly weakened spots in the concrete, and the dynamic loading appeared to have an effect of further weakening the damaged materials.

In general, higher release strengths led to less concrete damage in terms of both the potential to crack (maximum $d_{t}$ ) and the lengthwise extent of damage $\left(L_{\mathrm{dt}}\right)$. At the pretension release phase, while higher release strengths resulted in concrete damages with limited scope surrounding each prestressing strand, the concrete damages interconnected in the upper and lower strand planes, respectively, in the $3,500 \mathrm{psi}(24.1 \mathrm{MPa})$ release strength case, in a similar "horizontal" pattern observed in the field (Figure 1). However, Figures 9 and 11 indicate that there was similar or less potential to crack in the upper strand plane than in the lower strand plane, contrary to the fact that horizontal cracks were only observed in the concrete tie's upper strand plane in the field (Figure 1). To further examine the fastener effect on the cracking behavior, fastener modeling was introduced next.

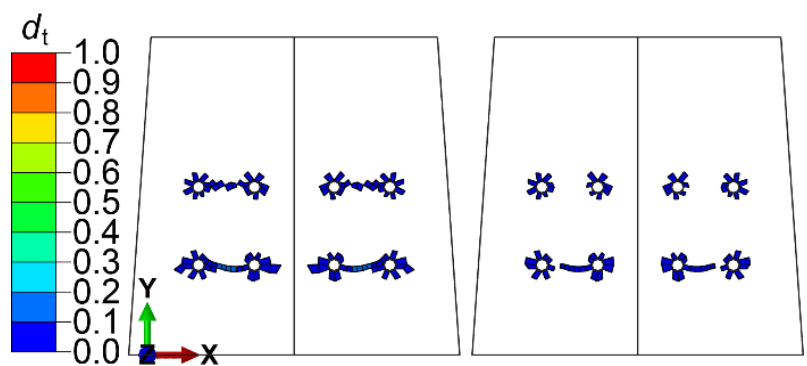

Figure 10: Tensile damage profiles $\left(d_{t} \geq 0.05\right)$ after pretension release at 4,500 psi (31.0 MPa, left) and 6,000 psi (41.4 MPa, right) release strengths without fastener installation.
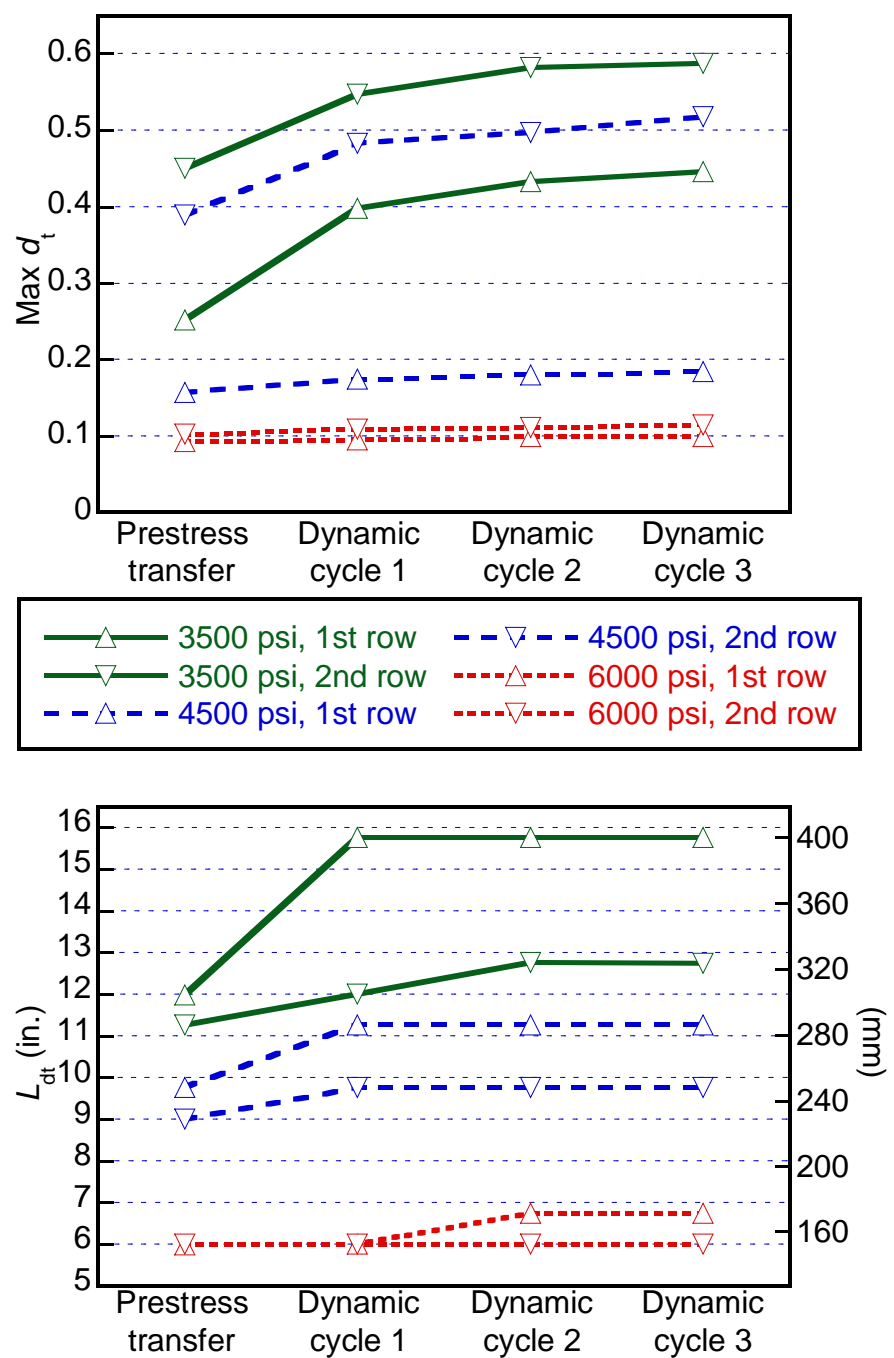

Figure 11: Evolution of maximum $d_{t}$ and $L_{d t}$ in planes across each row of strands in the pretension release and cyclic dynamic loading phases for all three release strengths, without fastener installation. 


\section{With fastener installation}

The fastener assembly model included two shoulders, two clips, two insulators, one rail pad and the rail. In a static FEA after pretension release, the clips were rotated clear of the insulators on top of the rail bases and then released to touch the insulators, resulting in a resultant toe load of 5 kips $(22.2 \mathrm{kN})$. Figure 12 shows the concrete tie model installed with the fastener and rail assembly. Half symmetry of the model about the center cross sectional plane was employed.

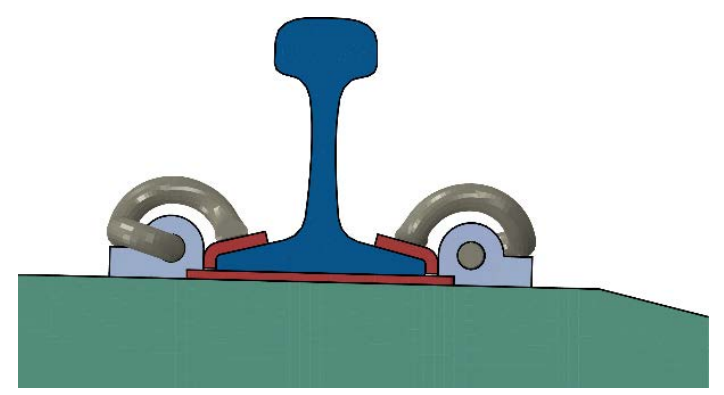

Figure 12: Concrete tie model with installed fastener and rail assembly.

Simulations with the fastener assembly were conducted first for the 3,500 psi (24.1 MPa) release strength. Figure 13 shows the tensile damage contours for all concrete elements satisfying $d_{t} \geq 0.05$ after pretention release/fastener installation and the first cycle of dynamic loading. Figure 14 further plots the evolution of the maximum $d_{\mathrm{t}}$ and the $L_{\mathrm{dt}}$ in all five phases (i.e., pretension release, fastener installation and three cycles of dynamic loading).

The fastener installation process did not appear to worsen the initial damages resulting from the pretension release, as both the maximum $d_{\mathrm{t}}$ and the $L_{\mathrm{dt}}$ remained the same after the fastener installation. However, the presence of the fastener shoulders in the concrete matrix appeared to alter the damage profile in the upper strand plane in comparison to that in the lower strand plane. The damages in the upper strand plane was interconnected across the plane, like the case without the fasteners. Unlike the case without the fasteners, the damages in the lower strand plane was disconnected. In addition, the maximum $d_{\mathrm{t}}$ assumed higher values in the upper strand plane than in the lower strand plane, especially after experiencing the dynamic loading. The presence of the fastener shoulders appeared to have an effect of redirecting the concrete damages to the upper strand plane, thus having the potential to reproduce the exact horizontal cracking pattern in the upper strand plane as observed in the field (Figure 1). Figure 14 shows that $d_{\mathrm{t}}$ kept increasing under dynamic loading and can conceivably approach 1 (i.e., crack formation) after a sufficiently large number of dynamic loading cycles.

Figure 15 shows the $d_{\mathrm{t}}$ contours after pretension release and fastener installation for the 4,500 psi (31.0 MPa) and 6,000 psi (41.4 MPa) release strengths. The effect of redirecting damages to the upper strand plane was not as significant but still discernable in comparison with Figure 10. The damage profile for the 4,500 psi (31.0 MPa) release strength appeared likely to develop into macro-cracks, but the partially disconnected profile and the lower maximum $d_{\mathrm{t}}$ meant it would take a larger number of dynamic loading cycles to crack the concrete tie than if the tie was produced under the 3,500 psi (24.1 MPa) release strength.
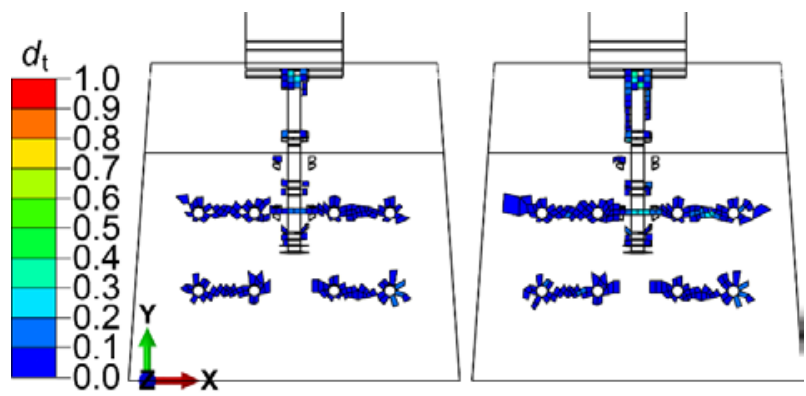

Figure 13: Tensile damage profiles $(d t \geq 0.05)$ at $3,500 \mathrm{psi}$ (24.1 MPa) release strength after pretension release and fastener installation (left) and first cycle of dynamic loading (right).
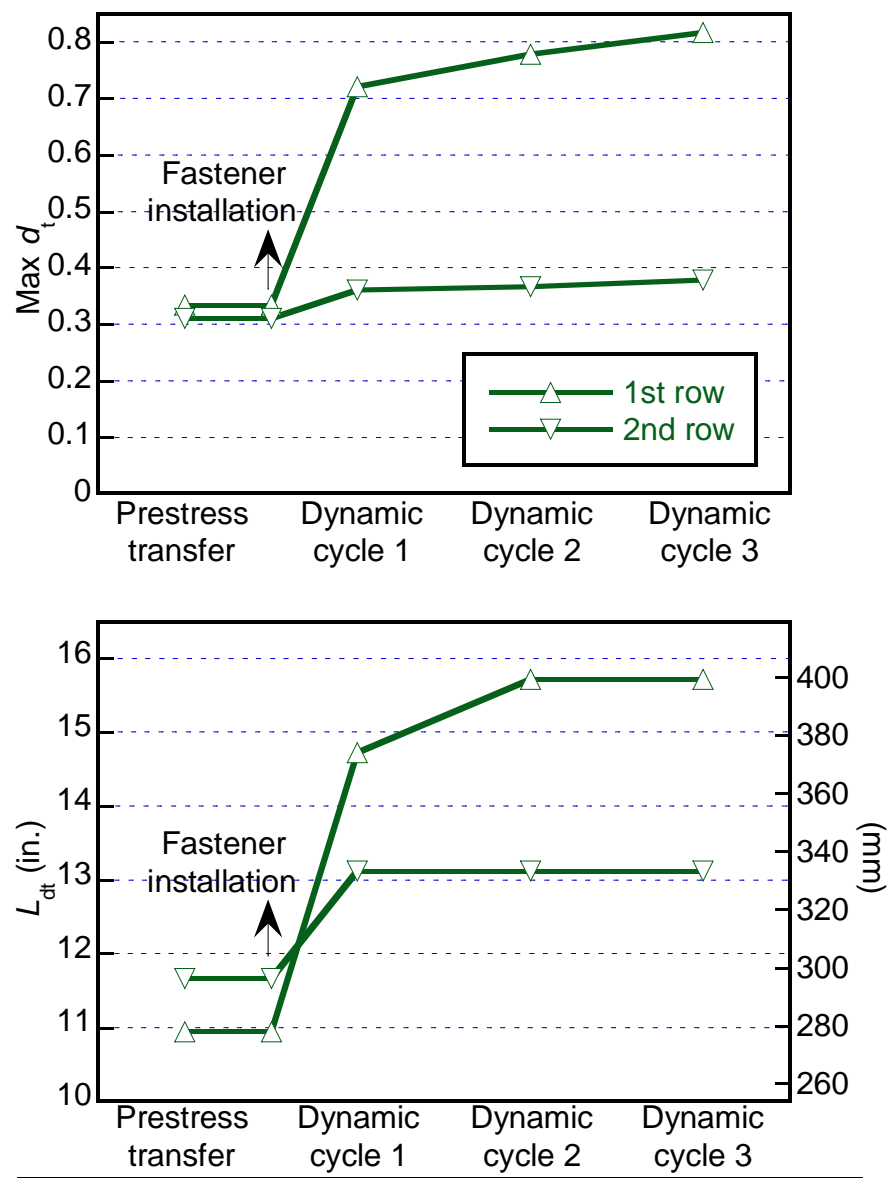

Figure 14: Evolution of maximum $d_{\mathrm{t}}$ and $L_{\mathrm{dt}}$ in planes across each row of strands upon pretension release, fastener installation and cyclic dynamic loading phases under the $3,500 \mathrm{psi}(24.1 \mathrm{MPa})$ release strength. 


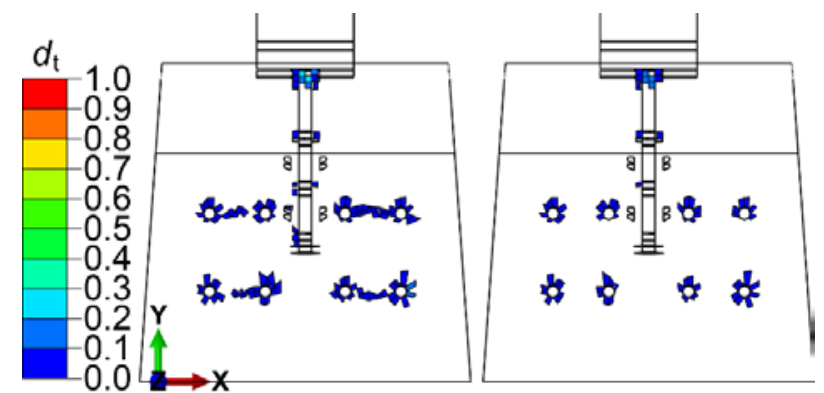

Figure 15: Tensile damage profiles $\left(d_{t} \geq 0.05\right)$ at 4,500 psi (31.0 MPa, left) and 6,000 psi (41.4 MPa, right) release strengths after pretension release and fastener installation.

\section{SUMMARY AND CONCLUSIONS}

An FEA framework for simulating the concrete crosstie behavior and evaluating their performance was applied to study the contributing factors to the horizontal splitting cracks found on a class of concrete crossties made with two rows or a total of eight prestressing steel strands. The static analyses of the prestress transfer and fastener installation processes indicated that low concrete release strengths during concrete tie production, coupled with the presence of fastener shoulders in the concrete matrix, led to the concrete material degradation predominantly in the upper strand plane upon pretension release. Dynamic analyses of the cyclic rail seat loading demonstrated that the initial damages in the upper strand plane could further grow in the degree of degradation and potentially develop into macro-cracks consistent with the upper strand plane, horizontal cracking pattern observed in the field. The results of this study can guide the experimental studies to verify the significance of these contributing factors. A better understanding of these contributing factors can help to develop performance based design standards that can prevent the recurrence of this failure mode in future concrete crosstie applications.

\section{ACKNOWLEDGEMENT}

The work described in this paper was sponsored by the Office of Research, Development and Technology, Federal Railroad Administration, U.S. Department of Transportation. Directions provided by Messrs. Gary Carr and Cameron Stuart of the Track Research Division are gratefully acknowledged.

\section{REFERENCES}

[1] Hanna, A. N., 1979, "State-of-the-Art Report on Prestressed Concrete Ties for North American Railroads," PCI Journal, September-October: 32-61.

[2] Yu, H., Jeong, D., Marquis, B., and Coltman, M., 2015, "Railroad Concrete Tie Failure Modes and Research Needs," 2015 Transportation Research Board 94th Annual Meeting, TRB15-0311.

[3] Mayville, R. A., Jiang, L., and Sherman, M., 2014, "Performance Evaluation of Concrete Railroad Ties on the Northeast Corridor," Report No. DOT/FRA/RPD-14/03,
Federal Railroad Administration, U.S. Department of Transportation.

[4] Yu, H., Jeong, D. Y., Choros, J., and Sussmann, T., 2011, "Finite Element Modeling of Prestressed Concrete Crossties with Ballast and Subgrade Support," Proc. ASME 2011 International Design Engineering Technical Conferences \& Computers and Information in Engineering Conference, DETC2011-47452.

[5] Yu, H., and Jeong, D. Y., 2012, "Railroad Tie Responses to Directly Applied Rail Seat Loading in Ballasted Tracks: A Computational Study," Proc. ASME/ASCE/IEEE 2012 Joint Rail Conference, JRC2012-74149.

[6] Yu, H., and Jeong, D. Y., 2014, "Bond between Smooth Prestressing Wires and Concrete: Finite Element Model and Transfer Length Analysis for Pretensioned Concrete Crossties," Proceedings of the 2014 ASCE Structures Congress.

[7] Yu, H., and Jeong, D.Y., 2015, "Finite Element Bond Models for Seven-Wire Prestressing Strands in Concrete Crossties," Proceedings of the 2015 Joint Rail Conference, JRC2015-5758.

[8] Yu, H., and Jeong, D.Y., 2016, "Finite Element Bond Modeling for Indented Wires in Pretensioned Concrete Crossties," 2016 Joint Rail Conference, JRC2016-5782.

[9] Yu, H., 2017, “A Unified Elastoplastic Bond Model for Prestressing Steel Reinforcements Used in Railroad Concrete Crossties," in preparation.

[10] Yu, H., Marquis, B., and Jeong, D.Y., 2015, "Failure Analysis of Railroad Concrete Crossties in Center Binding Conditions Using Finite Element Method," Proceedings of the Stephenson Conference, Institution of Mechanical Engineers, London, UK, April 21-23.

[11] Yu, H., Marquis, B., and Jeong, D.Y., 2016, "Failure Analysis of Railroad Concrete Crossties in the Center Negative Flexural Mode Using Finite Element Method," Part F: Journal of Rail and Rapid Transit, in press.

[12] Yu, H., 2016, "Estimating Deterioration in the Concrete Tie-Ballast Interface Based on Vertical Tie Deflection Profile: A Numerical Study," Proceedings of the 2016 Joint Rail Conference, JRC2016-5783.

[13] Dassault Systèmes, 2012, Abaqus Analysis User's Manual.

[14] Bodapati, N. N. B., Zhao, W., Peterman, R. J., Wu, C. H. J., Beck, B. T., Haynes, M., and Holste, J. R., 2013, "Influence of Indented Wire Geometry and Concrete Parameters on the Transfer Length in Pretensioned Concrete Crossties," Proc. 2013 Joint Rail Conference, JRC2013-2463.

[15] Arnold, M. L., 2013, Un-Tensioned Pullout Tests to Predict the Bond Quality of Different Prestressing Reinforcements Used in Concrete Railroad Ties. PhD Dissertation, Kansas State University.

[16] American Railway Engineering and Maintenance-of-Way Association, 2016, Manual for Railway Engineering, Chapter 30: Ties. 